\title{
A Pliocene fungal consortium in epithermal steam-heated grounds (Ixtacamatitlan, Mexico)
}

A. CAMPrubí ${ }^{1}, *$ E. Fuentes-GuZMÁN ${ }^{1,2}$, P. ORTEGALARROCEA $^{1}$, M. COLÍN-GARCÍA ${ }^{1}$, J. GABITES ${ }^{3}$, L.F. AUQUÉ$^{4}$, V. COLÁS ${ }^{1}$, E. GONZÁlEZ-PARTIDA ${ }^{5}$

${ }^{1}$ Instituto de Geología, Universidad Nacional Autónoma de México, Mexico; edithfuentesg@gmail.com

${ }^{2}$ Laboratorio Nacional de Geoquímica y Mineralogía, Mexico.

${ }^{3}$ Pacific Centre for Isotopic and Geochemical Research, University of British Columbia, Canada.

${ }^{4}$ Departamento de Ciencias de la Tierra, Universidad de Zaragoza, Spain.

${ }^{5}$ Centro de Geociencias, Universidad Nacional Autónoma de México, Mexico

The Ixtacamaxtitlán area in south-central Mexico contains middle Miocene porphyry/skarn $\mathrm{Cu}-\mathrm{Mo}-\mathrm{Au}$ and Pliocene AuAg low sulfidation epithermal deposits that are geologically associated with the evolution of the Trans-Mexican Volcanic Belt (TMVB). A new ${ }^{40} \mathrm{Ar} /{ }^{39} \mathrm{Ar}$ age $(2.87 \pm 0.41 \mathrm{Ma})$ in rhombohedral alunite from an advanced argillic alteration assemblage is provided. This age adds up to the definition of a metallogenic province that is circumscribed to the TMVB, which is a relevant feature for regional exploration. Alunite occurs in a spongy layer that consists of vertical tubular structures that are hereby interpreted as due to gas venting in a subaerial environment, i.e. steam-heated environment associated to the boiling dynamics in the epithermal veins below. Within the alunite tubular structures were developed consortia dominated by fungi and that also include distinctive biofilms by prokaryotes. The observed microstructures that are typical for fungi are septate hyphae with anastomoses, mycelium and hyphae forming cord-like structures without reproductive spores. Such consortia were developed on previously formed alunite and kaolinite, and were preserved due to their fossilization by opal, kaolinite or alunite. Bioweathering was possibly predated by inorganic partial solubilization of alunite, which denotes an eventual less acidic environment that allowed living organisms to thrive, at temperatures, $\mathrm{pH}$ and solute contents that are compatible with geothermal systems. Bioweathering of previously precipitated minerals is shown by penetrative biobrecciation due to extensive dissolution of kaolinite generated by mycelia and the development of dissolution grooves generated by hyphae on alunite surfaces. Fungal activity was particularly aggressive on kaolinite due to its relatively poor nutrient potential. 